\title{
An Action Research Approach to Workplace Health: Integrating Methods
}

\author{
Margrit K. Hugentobler, PhD \\ Barbara A. Israel, DrPH \\ Susan J. Schurman, PhD
}

Action research, which combines the generation and testing of theory with social system change, demands multiple sources of knowledge about the research setting and encourages the integration of data collection techniques. This article describes the implementation of a longitudinal multi-methodological research and intervention project aimed both at examining the relationship between occupational stress and psychosocial moderating factors (e.g., social support, participation, and influence over decision-making) and health outcomes; and reducing work stress and improving employee health. Combining qualitative and quantitative research techniques such as semistructured individual and focus group interviews, field notes and survey data increases confidence in research findings and strengthens the process and outcomes of needs assessment, program planning, implementation, and evaluation. Specific examples are provided that illustrate the usefulness of this approach in identifying and understanding problem areas and in developing and evaluating appropriate health education interventions.

\section{INTRODUCTION}

Just as "every cobbler thinks leather is the only thing-most social scientists have their favorite research methods with which they are familiar and have some

The action research project examined in this article was initially supported by grant no. 501 AA06553 from the National Institute on Alcohol Abuse and Alcoholism. The project is presently funded in whole by joint funds from UAW/GM National Joint Committee on Health and Safety. We also wish to thank members of the research team and the worksite Stress and Wellness Committee for their invaluable contributions to this project. We greatly appreciate the assistance of Sue Andersen in the preparation of this manuscript.

Margrit K. Hugentobler is Assistant Research Scientist, University of Michigan, Department of Health Behavior and Health Education, School of Public Health, Ann Arbor.

Barbara A. Israel is Associate Professor, University of Michigan, School of Public Health, Department of Health Behavior and Health Education, Ann Arbor.

Susan J. Schurman is Director, Labor Studies Center, University of Michigan, Institute of Labor and Industrial Relations, Ann Arbor.

Address reprint requests to Margrit K. Hugentobler, $\mathrm{PhD}$, Assistant Research Scientist, University of Michigan, Department of Health Behavior and Health Education, School of Public Heaith, Ann Arbor, MI 48109-2029. 
skill in using. [Consequently] . . we mostly choose to investigate problems that seem vulnerable to attack through these methods"' (p. 338). Trow's observation-made over 30 years ago-and his subsequent challenge that "we should at least try to be less parochial than cobblers," has only found more widespread support within the last decade.

But while the use of multiple methods has been proposed in various fields of applied social science, ${ }^{2-7}$ few studies have demonstrated how to meaningfully translate such research designs into health education practice. This article tries to fill this gap by describing the authors' efforts to implement a multimethodological research and intervention strategy in a longitudinal action research study aimed at investigating the relationship between workplace stress and health outcomes. Our goal is to illustrate how we have integrated qualitative and quantitative methods for the purposes of problem definition, illumination of meaning, and cross validation and triangulation.

Effective health education interventions involving multiple components such as needs assessment, program design and implementation, and program evaluation and diffusion, call for versatility in using different methods appropriate to the different tasks of the intervention. ${ }^{8}$ In addition, there is growing recognition in the field that successful health education interventions may be contingent upon an ecological approach that focuses attention on both individual and environmental determinants of behavior. ${ }^{9}$ A view of individual behavior as a function of the interaction of intrapersonal factors, interpersonal processes, and organizational and community factors embedded in broader cultural norms and beliefs, places new and more complex demands on research and intervention methods.

Within this context, the purpose of this article is to illustrate: (1) how the combined use of qualitative and quantitative data can increase confidence in research findings; (2) how multiple data sources can strengthen the process of program planning, needs assessment, intervention, and evaluation; (3) the strengths and limitations inherent in this approach; and (4) implications for health education practice. Thus the focus of the article is not on a detailed explication of either qualitative or quantitative data analysis techniques, but rather on the conceptual integration of procedures involved in using multiple methods in an effort to create a healthier work environment.

\section{AN ACTION RESEARCH APPROACH TO OCCUPATIONAL STRESS AND HEALTH}

The data used to illustrate various ways of using qualitative and quantitative methods are drawn from a six-year joint university/union/management action research project. This project is being conducted in a medium-sized (approximately 1,080 employees) component-parts manufacturing plant in Michigan.

A primary goal of action research is to involve researchers and organization members in a cooperative, cyclical process of diagnosing and analyzing problems, and planning, implementing, and evaluating interventions aimed at meeting identified needs. ${ }^{10,11}$ One of the distinguishing features of action research is that 
it entails both research and interventions. The research objectives of the project described here are: (1) gaining increased knowledge and understanding of sources of occupational stress; (2) exploring how employees respond to stress; (3) assessing the effects of stress on employees' well-being and identifying the factors that influence the stress process; and (4) evaluating the effectiveness of action research as a means of improving employee health. The intervention objectives are aimed at: (1) changing stressful features of the work environment so as to reduce the levels of stress experienced; (2) helping organization members learn how to manage stress; (3) "buffering" or mitigating the impact of stress on health; and (4) promoting health and thus counteracting the negative effects of stress.

The project is based on a conceptual model informed by prior research that conceptualizes occupational stress as a process in which individual and environmental sources of stress, (e.g., work overload, shift work) are associated with a variety of physiological, psychological, and behavioral outcomes. These shortand long-term responses to stress are potentially moderated by a number of key factors such as social support, personality, biophysical characteristics, and genetic predisposition (see Fig. 1). ${ }^{12-17}$

Though guided by this theoretical model, the particular sources of stress targeted for interventions have been defined by the participants in the site through an open-ended exploratory process. The project combines research and interventions for which multiple types of data have been collected at various points in time over the last five years. Such longitudinal data can address questions of causality often remaining unanswered in the largely cross-sectional nature of prior research in this area. Comparing baseline data with a detailed documentation of interventions and the examination of key variables such as social support, participation, stress, and health at different points in time create the potential for an assessment of both the causal relationships among these variables, and the extent to which changes in these variables can be attributed to the interventions.

Action research emphasizes a participatory approach which involves researchers and organization members in a joint cooperative process. In the present study, after entry discussions with both divisional and plant management and local and plant union officials, a working committee was organized, according to criteria jointly developed by union, management, and the university team, to guide the project. The Stress and Wellness Committee (SWC), the name the action research group chose for itself, is made up of representatives from key groups within the plant, (e.g., hourly production and skilled trades workers such as assemblers and electricians from different work areas and shifts, management representatives from different levels, union officials, men and women, black and white). Other selection criteria included that representatives should be trusted and respected by others, knowledgeable about the plant, and able to communicate well with different groups in the organization. This committee has worked closely with the research team, meeting at least twice a month, on every phase of the project (e.g., data collection and analysis, intervention design, implementation, and evaluation).

The project is currently in its sixth year. Three waves of plant-wide survey 


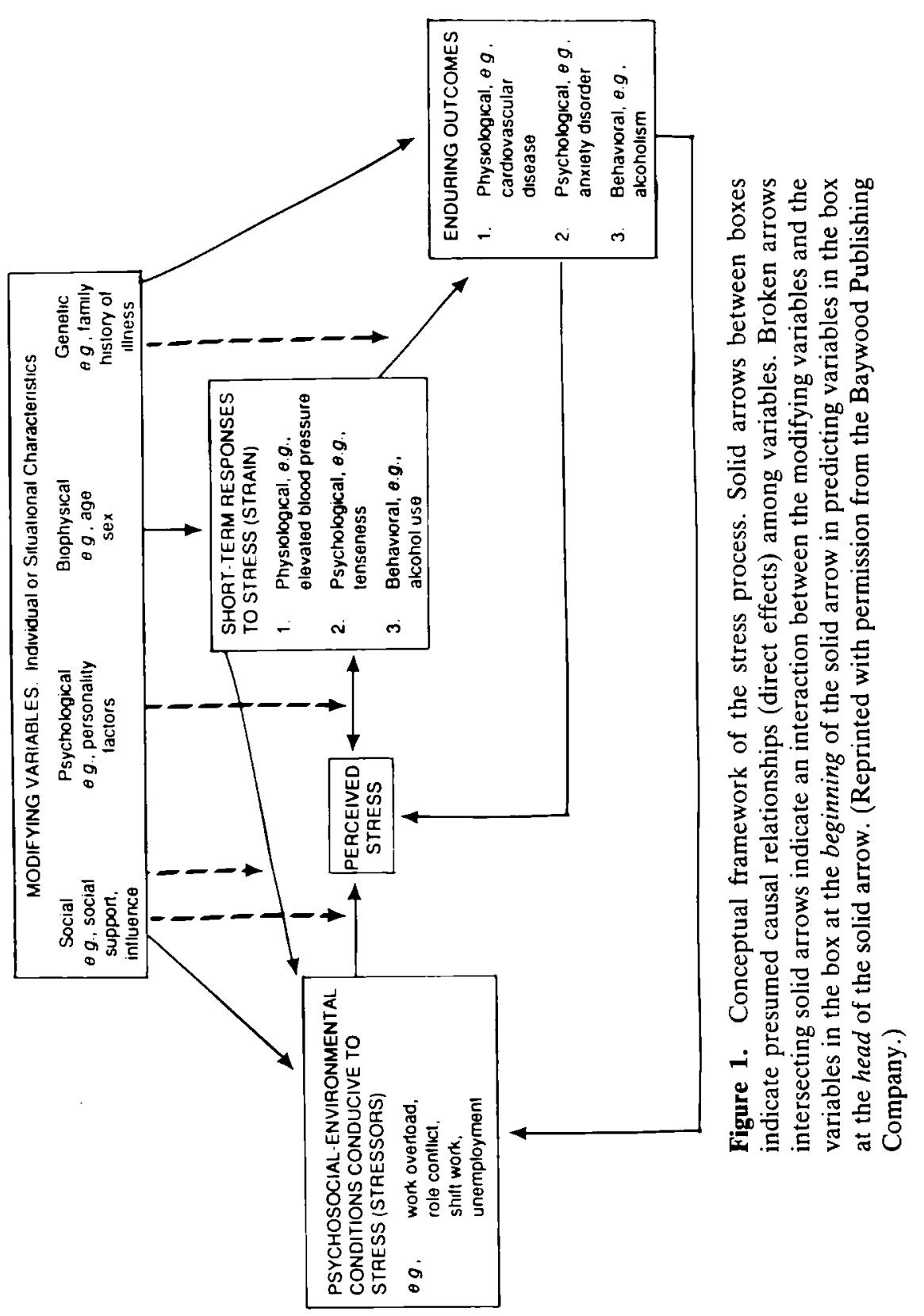


data have been collected and analyzed along with various surveys of subgroups and multiple types and sources of qualitative data. A number of interventions have been implemented or are in the implementation stage at this time. ${ }^{17}$

The discussion below presents an overview of the different methods used for achieving the various research and intervention goals. This will be followed by specific examples illustrating how we have combined quantitative and qualitative data for organizational needs assessment and intervention purposes.

\section{DATA COLLECTION METHODS}

The major issue in a multi-method study is not one of "the more methods the better," but rather what types of data collection methods and data sources are best suited to answer the research questions, and to provide the information necessary to guide interventions in the context of action research. Although the initial research design proposed the use of different methods for different project phases and purposes, decisions to collect additional qualitative and quantitative data from various sources were made throughout the project as the need for specific information arose. The four major data collection techniques that we have used are: individual interviews, focus group interviews, field notes of committee meetings, and survey questionnaires.

\section{Individual Interviews}

In order to gain an understanding of the organization, the authors conducted in-depth semi-structured interviews with 42 individuals during the first four months of the project. In addition to the 26 committee members, these "key informants" included all members of top plant management and the plant-level union "shop committee." Interviews, which were tape recorded, lasted an average of $1 \frac{1}{2}$ hours. A semi-structured interview protocol typically consists of a combination of broadly-framed open-ended questions followed by more specific probes. For example, one question asked participants "what is your job (describe a typical work day)," followed by probes, such as, "how often do people have more work to do than time available." Thus while the questions were designed to address a given set of topic areas (described below in the organizational needs assessment section), they could be expanded and modified as new or unexpected issues of relevance emerged during individual interviews. ${ }^{18}$ In one interview, for example, the focus became the stressful aspects of being a female employee in a traditionally male-dominated work environment.

An edited written version was prepared for each interview. These data provided a rich source for the preliminary identification of the major problem areas in the organization. Following procedures suggested by Miles and Huberman, ${ }^{19}$ the data were then analyzed in order to identify relevant themes or categories embedded in the text. The categories we identified were: the type of problem, the reason it exists, problem effects, current problem solution strategies, solution effects, and proposed alternative strategies. By analyzing all of the interview data in this way we were able to assess how frequently specific problems were 
mentioned, and how they were currently addressed. We also developed a preliminary understanding of the problem-solving approaches typical for the plant.

\section{Focus Group Interviews}

A focus group interview is aimed at uncovering feelings and opinions about a specific topic of interest or eliciting reactions to proposed solutions. ${ }^{20,21}$ It typically involves a group of 8-10 persons with similar characteristics (e.g., shop floor workers or supervisors) and similar experiences in relationship to the topic addressed. This approach was used in SWC meetings and in meetings with other subgroups in the plant to supplement and help interpret quantitative data in the context of action planning as well as evaluation. A focus group discussion was conducted, for example, to explore why some of the past employee involvement programs had failed. The SWC members compiled a list of the key programs and the research team then asked the committee a set of open-ended questions about each program, such as: What was the program's purpose; what were the key activities; who was to benefit; how was the program implemented; what were the program's strengths; and what were its weaknesses? Analysis of verbatim records from this discussion identified committee members' opinions regarding key factors central for program success. Emerging core themes like "programs need to have commitment and support from management" or "participants should receive information and feedback on their actions and on the program's development" were subsequently integrated into a set of recommendations (often termed a "local theory of action") ${ }^{22}$ for developing successful programs within the organization.

\section{Field Notes}

To document the project's process and progress in as much detail as possible, we have kept ethnographic field notes of all major contacts with the research site. These field notes consist of as close to verbatim as possible descriptions of events. To protect participants' confidentiality, all names are deleted from the transcripts and code numbers are inserted. To ensure accuracy and to protect against single observer bias, the notes are then circulated among the research team for changes, additions, and observations about the project's development. The notes have also served as a useful means of orienting new staff members to the project's history and development.

All research team members were trained in the process of taking field notes and on the purpose of collecting and utilizing multiple data sources. Analysis of the field notes for the exploration of different themes emerging as relevant for intervention and research purposes followed procedures similar to those suggested by Whyte ${ }^{23}$ and Chesler ${ }^{24}$ For example, first, field notes were reviewed for paragraphs relevant to the topic of interest; next, the key content was restated in the margin of each paragraph (in vivo coding) using the same words as they appeared in the text; two to three codes were then assigned to the paragraph reflecting the key issues that emerged from the text; finally, these codes were 
grouped into broader themes that were summarized using quotes from the actual field notes. The goal has been to preserve the informants' "voices" in the data analysis and interpretation process rather than substituting the research team's interpretation.

\section{Survey Data}

The research design includes the administration of three surveys to the total plant population. These three waves of data collection were conducted in April 1986, June 1987, and April 1991.* These data serve the multiple functions of a broad-based needs assessment that includes everyone in the plant, tests of major research hypotheses, and evaluation of intervention outcomes. The survey instrument includes questions on variables in the conceptual model, for example, sources of stress, social support, participation and influence, job satisfaction, depression, and overall health (see Fig. 1). Survey results presented in this article are drawn from the first plant-wide survey conducted in April 1986. Six hundred eighty (680) hourly and salaried employees or $66 \%$ of the total plant population completed this survey. A series of factor analyses were conducted on the major classes of variables and based on the results, multi-item indices were constructed. Additional indices were created by adding the responses of constituent questions from previously validated scales. Several of the key research questions have been examined using multiple regression analyses. ${ }^{25,26}$

\section{INTEGRATION OF QUANTITATIVE AND QUALITATIVE DATA}

As some writers have warned, the combination of methods does not necessarily eliminate bias or guarantee internal and external validity. Hence "what is involved ... is not the combination of different kinds of data per se, but rather an attempt to relate different sorts of data in such a way as to counteract various possible threats to the validity of data analysis"27 (p. 199). A major strength of action research is the opportunity to use many different sources of evidence in an effort to develop converging lines of inquiry, sometimes termed triangulation. ${ }^{28,29}$ This is important since action research projects like this one often involve single cases with no realistic possibility to employ a control group. In such cases, construct validity can be strengthened through the use of multiple measures to investigate the same phenomenon. ${ }^{30}$ Yet, the specific manner in which the combination of quantitative and qualitative data has guided action research strategies is rarely clearly explicated. Neglecting to do so compounds the difficulty such projects already face in attempts to link interventions to behavioral and structural outcomes in the often unpredictable, turbulent context of organizational settings.

Throughout the different project phases we have drawn on multiple data sources, referring to earlier data and collecting new data as necessary based on the project's development. The integration of qualitative and quantitative meth-

*Copies of survey instruments are available from the authors. 
ods was guided by three aims suggested by Ingersoll-Dayton ${ }^{31}$ : (1) problem definition; (2) illumination of meaning; and (3) cross validation and triangulation. The following section illustrates the integration of multiple methods in more detail, using the organizational needs assessment as a research example and some of the four major sources of stress the committee decided to work on as intervention examples.

\section{ORGANIZATIONAL NEEDS ASSESSMENT}

\section{Problem Definition}

One of the major purposes of using multiple methods is to gain an increased understanding of the nature of the problem. In the early stages of this project, qualitative data collection techniques were central to the exploratory process of defining problem areas. We used the in-depth interviews and field notes in conducting an initial organizational diagnosis. The purpose of this phase was to gain knowledge about the history of the organization, its structure, culture, problem areas, and perceived sources of stress. The open-ended interview questions focused on organizational culture and structure (e.g., decision-making processes, communication patterns, organizational norms); identification of problems at work or sources of stress and ways in which they are dealt with; descriptions of characteristics of different jobs in the plant; positive aspects of work and sources of job satisfaction; and interpersonal relationships at work among different subgroups.

Information gained in these interviews appeared to reflect the elements of the conceptual model guiding this project, that is, social support, participation, influence, and individual and group coping and problem-solving abilities emerged as important factors influencing how job-related stress is perceived, handled, and its effects on employee well-being.

While providing an organizational assessment and a preliminary definition of problems, these interviews also helped develop trusting relationships between the researchers and SWC members and key plant and union leaders, a crucial factor in action research. ${ }^{32}$ These interactions were also intended to strengthen the mutual ownership of the project through developing a joint definition of problems along with a common understanding of the project's goals among SWC members, organization leaders, and the research team. Thus, the early qualitative data collection also served important intervention goals.

In addition to painting a comprehensive picture of the research site, the interview results pointed to a series of major sources of stress in the plant which guided the development of survey questions for the subsequent plant-wide survey. Section $A$ in Table 1 shows some examples of the key problem areas that emerged from the interviews, categorized according to topic area such as equipment problems, insufficient information and communication, and lack of influence and control over decision-making. Survey questions were then developed on these topics in order to determine the extent to which these concerns affected employees throughout the plant. In this process, standardized, validated survey items to assess the key concepts of our theoretical framework (i.e., Fig. 1) were 
complemented by a set of questions that specifically addressed the problems that were identified in the interviews. Some examples of such survey items are: Product Quality Problems: "How often are you bothered by feeling pressure to run parts out of [that do not meet] specification in order to meet production quotas"; Job Harassment: "How often are you bothered by harassment due to your sex or race."

Building on the qualitative data, the first plant-wide survey served as a broad-based needs assessment to further determine problem areas for potential intervention. Results from an open-ended survey question, asking employees about their biggest source of stress, as well as closed-ended items asking about "how often people are bothered by certain situations at work" pointed to concerns very similar to those identified earlier in the in-depth interviews: problems with people, equipment and material problems, job demands and pressures, and job security (compare Sections A, B, and C in Table 1). The survey therefore allowed for an assessment of the importance and generalizability of the problems raised in the interviews for the plant as a whole, in addition to providing the quantitative baseline dataset for research purposes.

\section{Illumination of Meaning}

The second reason for collecting both qualitative and quantitative data was to use the interview data to clarify and interpret the results of the survey. While the survey data supported our interview findings, qualitative information from the interviews helped us understand some of the more puzzling survey responses, thereby illuminating the meaning of some of the survey findings. For example, several questions were asked on the survey about job satisfaction and positive feelings about the job. Six items were used to construct an index on job satisfaction (reliability coefficient $=.84$ ). ${ }^{*}$ Given the numerous sources of stress reported in the survey and interviews, many members of the SWC were surprised by survey responses indicating that over $60 \%$ of hourly employees and $50 \%$ of salaried employees were "often" or "almost always" satisfied with their jobs. Analysis of the qualitative interview data regarding positive aspects of work helped us understand and interpret what otherwise seemed to be conflicting results. In the words of the interviewees, positive aspects of work included:

1. Salary and benefits: "Money is very good. Benefits, I guess I don't know of any that are better."

2. A sense of accomplishment and challenge: "Not everybody can do my job. It requires some talent. It's not monotonous and boring." "You get a sense of accomplishment when you do something right, fixing something that has been down."

*The six items used to construct the index on job satisfaction assessed: overall job satisfaction, whether the respondent would recommend the job to others, whether the respondent would decide to take the job again, and how frequently the respondent felt happy, contented, and proud about work. This and other multi-item indices referred to in this article were constructed on the basis of the results of factor analyses except where indicated. An overview of component items, response scales, and estimated internal consistency reliability coefficients can be obtained elsewhere. ${ }^{25}$ 


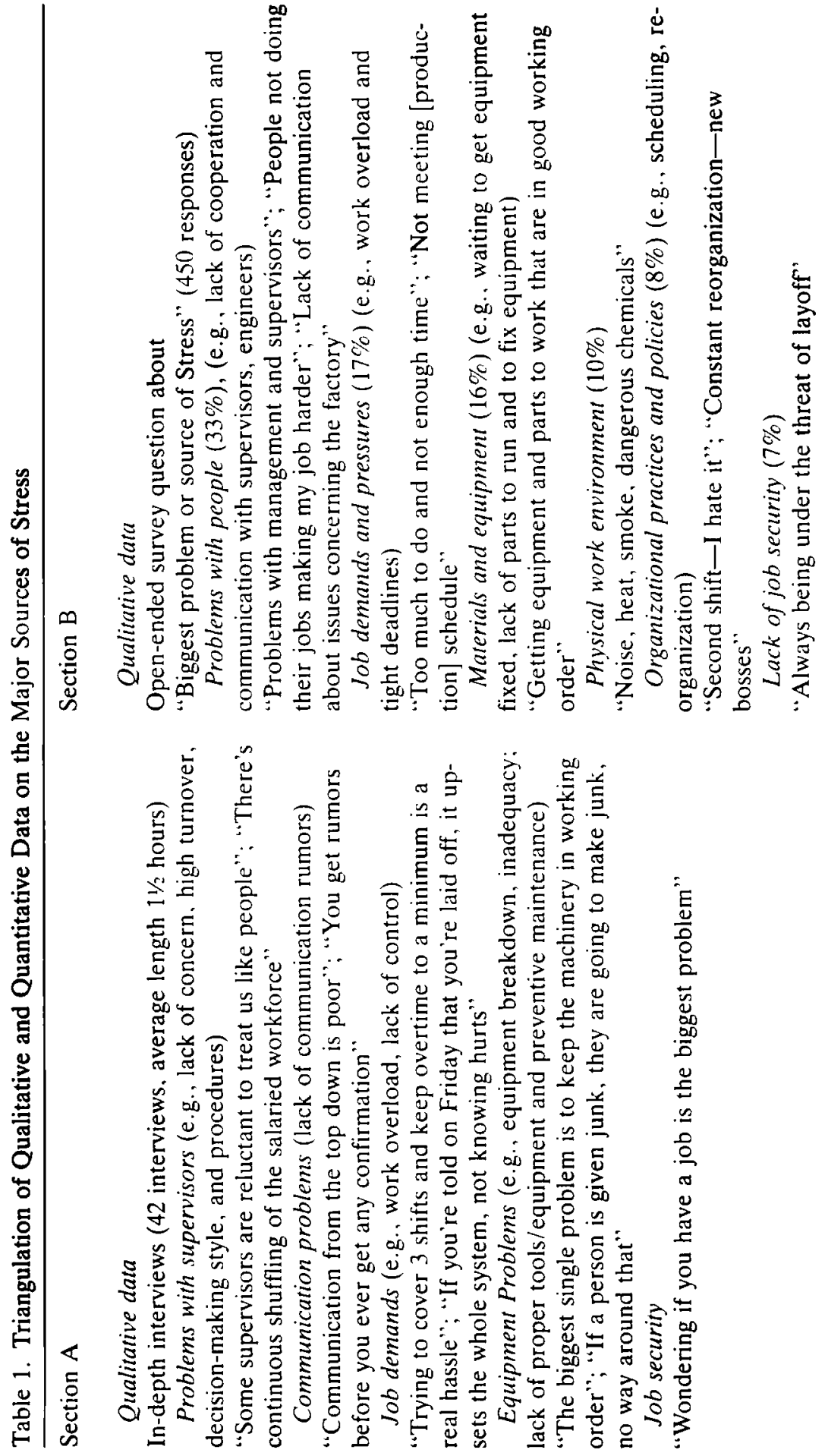




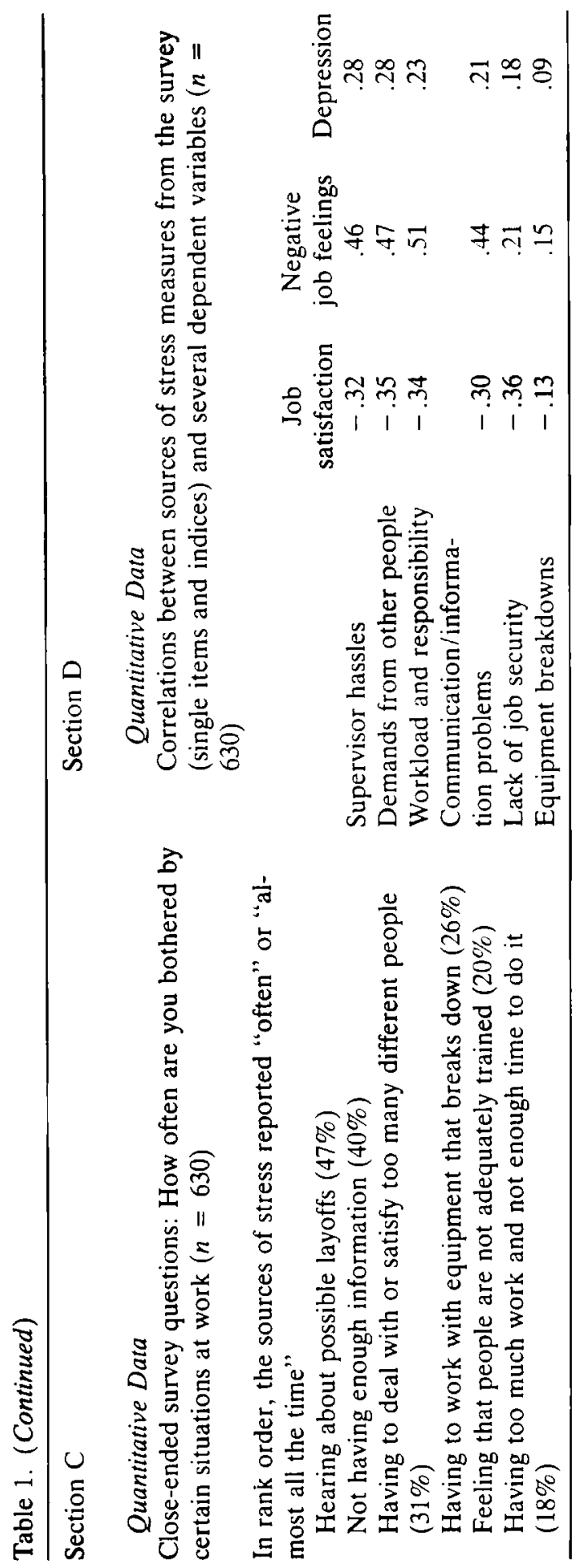


3. A feeling of familiarity with the environment: "I know the building. I know the people." "I feel at home here .. I I like where I am."

Other positive aspects mentioned were: a sense of making a contribution to the plant; cooperation with coworkers; no time clocks; the programs offered; opportunities for involvement, and specific types of work (machining vs. assembly jobs). The attitudes toward jobs that emerged from the qualitative data suggested that jobs might be perceived as satisfying overall in spite of the presence of numerous stressful aspects in the work situation. Understanding this more complex picture in which most people did not perceive their jobs as either completely satisfying or stressful helped the SWC and the researchers to more carefully target intervention activities.

\section{Cross Validation and Triangulation}

The third purpose of collecting both qualitative and quantitative data is for triangulation-the use of the two methods concomitantly in order to provide cross validation. Triangulation is broadly defined by Denzin" as "the combination of methodologies in the study of the same phenomenon," and Jick ${ }^{33}$ suggests that "the effectiveness of triangulation rests on the premise that the weaknesses in each single method will be compensated by the counter-balancing strengths of another" (p. 604).

Our collection of qualitative and quantitative data indicated considerable convergence on the major sources of stress within the plant, increasing our confidence that we had indeed tapped the important issues. The similarity of findings also suggested that the qualitative data, based largely on interviews with SWC members, did not suffer from an "elite bias," the common pitfall of qualitative data collection noted by Sieber ${ }^{34}$ Although members of this committee had been "handpicked" based on criteria proposed by members of management and the union, the similarities in the results of the interview and survey data strengthened our earlier belief that the committee was indeed representative of the plant population. This convergence of the qualitative and quantitative findings was particularly important as it provided the basis for the subsequent interventions recommended by the SWC aimed at alleviating some of these problems.

More than two-thirds of the respondents answered an open-ended question in the survey asking about their "biggest work-related problem or source of stress." Coded and rank ordered, these responses were consistent with the sources of stress that were identified in the in-depth interviews (compare Sections $A$ and B, Table 1). Furthermore, analysis of the closed-ended questions in the survey that assessed sources of stress, allowed for comparisons across single items that used the same lead in and response categories. For example, people were asked "how often they were bothered by" certain situations at work. The sources of stress that received a high percentage of answers in the categories "often" or "almost all the time" again pointed to the same key concerns reflected in the interviews and the open-ended survey question (see Section C, Table 1). 
Finally, "sources of stress" measures from the survey, including single items and indices, were analyzed in relation to several dependent variables. Not surprisingly, some of the same key concerns noted in the interviews and open-ended survey questions proved to be significantly correlated with outcome variables such as job satisfaction, negative feelings about the job, and measures of psychological well-being (see Section D, Table 1). Further analyses that tested the multivariate conceptual model also identified some of the same sources of stress as explaining a significant amount of the variance in the outcomes examined.$^{25}$ As illustrated in Table 1, the comparison of qualitative and quantitative data from different sources yielded considerable convergence on the major sources of stress in the plant. This gave us and the committee greater confidence in the validity of our findings from the diagnosis phase of the project and set the stage for developing interventions.

\section{INTERVENTIONS}

The research team prepared a written report to the SWC containing the results of the survey and the in-depth interviews. Tables and charts presenting quantitative results were accompanied by qualitative data that described the different problem areas and helped the committee understand and interpret the meaning of the quantitative findings. For example, following a table from the survey data that indicated that $56 \%$ of hourly employees were "sometimes," "often," or "almost all the time" bothered by not getting enough information and feedback, interview quotes were included to illustrate different aspects of the information/ feedback problem: "Sometimes you talk to the supervisor and he talks to somebody higher up; normally things get lost that way"-or- "The problem is the interpretation of information; as it gets through the chain it gets distorted. Each individual has his or her own network to get information." By illustrating the more abstract quantitative concepts with concrete examples in organization members' own words, the problems became "real," reflecting people's actual experiences.

During a two day planning meeting, the committee and the research team examined these results in order to identify the magnitude of the problems and their effects. Based on these findings, the SWC identified four major problem areas as initial focal points for intervention: (1) lack of information, communication, and feedback; (2) problems with supervisors; (3) lack of participation in and influence over decision-making; and (4) conflict between producing quality versus quantity of product.

The SWC decided to form four subcommittees which would each address one of the targeted problem areas. The work of these subcommittees resulted in a set of multiple action recommendations which are currently being implemented. Not only did the selection of these problem areas for intervention evolve from the integration of qualitative and quantitative data analysis, the interweaving of multiple data sources continued to guide the steps of developing, implementing, and evaluating interventions. The following section illustrates this process by providing a brief description of interventions aimed at addressing these four major sources of stress. 


\section{Lack of Information/Communication/Feedback}

Initially, the information/communication subcommittee prepared a written report summarizing the key findings of the first survey and interviews. This report was mailed to employees' homes. The subcommittee then focused on the development of a daily newsletter containing updated plant information that was prominently placed on 10 newly built display cases distributed throughout the plant. One year later, in the second plant-wide survey, the subcommittee added several questions to assess the usefulness of the daily newsletter. Responses indicated that information and communication issues continued to be a major source of stress, and only about half of the employees said that the daily newsletter met their information needs.

In discussing these results and their own information needs, the committee realized increasingly that one-way communication-just putting out information-was an insufficient strategy to address the problem. Setting out to explore the issue in more detail, subcommittee members first developed their own mini-survey (no help from the research team) and then conducted a number of interviews with representatives of different groups in the plant, asking them what they liked or disliked about the newsletter and how it might be improved. The results indicated that the newsletter was perceived as being of limited value as the following comments illustrate: "people don't read it, they need more information on how the plant is run" or "the newsletter is good for telling people that we will have 25 layoffs next week; but where questions and answers come in-who are these 25 people and whether it's them-it may be creating more stress because people have nowhere to follow-up on what they read."

A subsequent focus group session with the full SWC identified the key ingredients essential to effective communication: communication has to be one-on-one, face-to-face, allowing for two-way interaction; information has to be credible, understandable, and relevant to particular jobs or departments; employees want to know where the plant is headed; and opportunities for asking questions and getting answers have to be provided.

Based on this revised local theory of effective communication, the subcommittee recommended that publication of the daily newsletter in its current form be suspended and replaced by a four-pronged information/communication strategy encompassing the following elements:

1. "Rumor Mill": Once or twice a month a top management and union official will be available for one hour in a specially designated room for employees to walk in and ask questions about any job or business-related subject. Questions and answers for each session will be posted on a bulletin board and-depending on the importance of the issues addressed-distributed throughout the plant in a special newsletter edition.

2. Quarterly update meetings: All employees will be invited to attend quarterly information meetings in which top management and union representatives provide information about the state of the business and future plans. Time for questions and answers will be built into the schedule.

3. Department meetings/information bulletins: Quarterly meetings should be complemented by weekly meetings between the supervisor and a designated 
team leader (hourly employee). Occasional bulletins should be prepared by supervisors to pass on relevant information to department employees.

4. Special information bulletins: Special updates and bulletins will be distributed to all members of the plant on an as-needed basis.

The original action recommendation of the subcommittee-the publication of the daily newsletter-reflected the established communication pattern of this organization, that is, to send out memos and bulletins with no attempt to obtain feedback on whether the information has been understood or is considered relevant. It was the findings from the second survey indicating that the information/communication problem persisted in spite of the newsletter that prodded the committee to rethink the issue. The subcommittee's use of additional data collection techniques such as individual interviews with plant members and a focus group discussion among its own members pointed to new, more effective ways to improve communication and information in the plant.

\section{Quality/Quantity Conflict and Lack of Participation and Influence}

The subcommittees exploring the two other major sources of stress, that is, lack of participation in and influence over decision-making, and conflict between producing quality versus quantity of product, recognized that these sources of stress, along with supervisor problems, were interrelated concerns that needed to be addressed simultaneously. In yet another example of local theory development, the research team facilitated a "process analysis," 35 involving both the subcommittee and the full committee, in which the group began to understand how these different stressors reflected an underlying system in which the parts were connected such that to change one required changing the others. This was a new insight in an organizational culture characterized by attention to discrete parts rather than systemic relationships. As a result, the SWC decided to design a pilot intervention involving a problem-solving team aimed at addressing the systemic issues.

The goals of this pilot project were: to improve quality and quantity ratings and to eliminate waste; to increase participation and influence over decisions on the job; to increase trust and improve relationships between supervisors and supervisees; and to identify and document the key factors important for the success of such a project in a process of ongoing evaluation. These goals were to be achieved through the formation of problem-solving teams whose purpose would be to identify quality problems and work together to solve them. As the name suggests, the pilot project was to be implemented in one department so that the plant as a whole could learn from its successes and failures.

The goals outlined in the proposal for the pilot project, which were submitted to and approved by top union and management in the organization, were derived from both quantitative (plant-wide survey) and qualitative (individual interviews) data. Next, a department was selected based on a number of criteria such as, product life cycle, department size, job volume, current equipment and quality problems, and department members' concern about quality. A project "steering committee" made up of the product area manager, union represent- 
ative, maintenance supervisor, and shift supervisor, was formed to give overall direction to the problem-solving team and to oversee the diffusion process if the approach was judged successful. Although we had hoped to form at least one team on each shift, only the second shift initially produced enough volunteers. The team itself consisted of eight department members who volunteered to participate, including production and skilled trade workers, an engineer, and the department supervisor.

At the first team meeting, the SWC "pilot project" subcommittee members presented the project proposal to the team members. Data from the first plant-wide survey were used to explain how the project idea was conceived. At the end of the meeting, participants were asked to complete a closed-ended questionnaire that assessed the meeting process, member participation, expectations about the project, how in their view the team should work together, and reasons for volunteering to participate in this project. An open-ended question asked for additional comments. This information provided baseline data against which the team's progress could be compared later.

Following an initial training phase in problem-solving, team building, and statistical process (quality) control, the team identified a list of problems associated with producing quality parts. The team met weekly or biweekly to discuss various aspects of the problems identified and developed and assessed steps taken to address them. Engineers, outside part and equipment suppliers, and other technical experts were invited to the meetings as needed in order to provide more information regarding specific issues. The team kept minutes of each meeting, recording its progress on actions taken, problems encountered, and next steps.

Six months and 18 months after the project started, the team completed a process evaluation survey to assess the project's effectiveness in solving quality problems through increased participation and influence in decision-making, and to detect barriers to the team accomplishing its objectives. Following the completion of the 18 month evaluation survey, a focus group interview was conducted with the pilot project team addressing three sets of questions: (1) what have been the major accomplishments/successes of the project? (2) what barriers/ problems/failures has the team faced? and (3) what are recommendations for improving the effectiveness of problem-solving teams? The purpose of this focus group interview was twofold; first, to assess the project's progress and problem areas to be addressed; and second, to provide information from which recommendations could be developed for the planned diffusion of this approach to other departments in the plant.

The results of the evaluation suggested that the team had grown into a cohesive and committed work group and had been very successful in establishing a problem-solving process characterized by mutual trust and openness. In the third survey, all team members responded that "a lot" of trust and openness existed among members, and the degree to which members felt comfortable expressing their opinions and felt that members listened to others' point of view had increased considerably over time. These positive outcomes were reiterated during the focus group discussion in statements, such as: "through all of this we have stuck together and in that it is a large success," and "I think that this group works well together." 
These positive comments about the group's process and the learning that had occurred, however, were contrasted with a variety of barriers that had limited the team's success in achieving its quality improvement goals. Less than half of the team members (43\%) "agreed" or "strongly agreed" that the team had the authority to carry out its solutions/recommendations, and 55\% thought the team had selected problems to work on that are too large for the group to solve. The subsequent focus group discussion highlighted the reasons for this critical assessment:

1. Lack or delay of sufficient information and cooperation from suppliers, vendors, engineers, and people working on other shifts. "I liked what we accomplished but we did not accomplish as much as we could have because there was not enough cooperation from people. We picked a problem and we were left dry from the vendor . . . they did not follow through and they think that we did not do enough." or "People on first shift think they run the show, first shift always thinks that they do all the work and not second." and "I think some people, let's say with engineering, people saw that we were onto something and they did not want us to uncover their dirty laundry so better that they get us off."

2. Other people interfering with the team's work and taking the problem the team identified away from them. "We would start the ball rolling and all sorts of people would want to take the project over and move us down the line." or "Today we are still doing the same thing we started with and all has been taken away from us with the pallet study and the tabs, and we have moved on to robots now."

3. Insufficient support from and communication with the steering committee (union and management). "The last time top management was here, there was surprise there had not been more getting done. One should have been able to tell by the minutes, but I think we may need to be in contact with management more than we have been in the past." or "We have had delays, but everything you do around here gets delayed, so that's not out of the ordinary. Anything you do yourself you can accomplish as long as you don't have to rely on anyone else."

Ongoing analysis of the field notes documenting this process by the research team suggested a number of other difficulties that had exacerbated the problems encountered by the team: (1) the initial problem elected by the team, although seemingly simple on the surface, turned out to be a very difficult problem to solve, requiring sophisticated engineering expertise; (2) the original union/management steering committee stopped functioning after a key manager who had championed the effort left the facility; and (3) the existence of only one team (on second shift) made communication and coordination with the first shift difficult. ${ }^{*}$

*The research team had been well aware at the project's inception of evidence that suggests that change-related interventions require a certain level of "intensity" (e.g., number of employees participating. frequency of meetings, level of top management and union support, and visibility) in order to have an impact..$^{3+2,34}$ However, at the time the pilot was planned it appeared that these conditions would be satisfied. This illustrates the difficulty involved in following the "prescriptions" in the intervention literature. 
The SWC used the knowledge gained from this evaluation of the pilot project to develop a set of recommendations for how to establish similar problem-solving teams in other departments. The recommendations addressed a set of key concerns presented as the ingredients necessary for a successful team problem-solving approach. Some excerpts from these recommendations are:

- The team should include a cross-section of people such as supervisors, skilled trades employees, and engineers associated with whatever product the group produces.

- Communication has to be ongoing, including face-to-face communication within the group and between the team and other groups.

- Team leadership/facilitation needs to be joint (union and management) and requires group-approved team leadership with group process skills.

- Training must be specific to group activities and needs.

- Responsibilities must be shared and a steering committee needs to advise and monitor the group's activities.

These recommendations were presented to and initially favorably received by the top union and management in the plant. However, a recent change in top management has forced the committee to confront its standard approach to change implementation. Rather than trying to develop recommendations based on its understanding and then getting these adopted, the committee has begun to realize that its emphasis will have to be on replicating the process of self-design and learning that enables other organization members to arrive at their own understandings (see e.g., 32). This has proved an exceptionally difficult task in an organizational environment that has traditionally paid little attention to process-type interventions. However, at the time of this writing, a process has been created that draws upon the SWC's recommendations to establish problem-solving teams in other departments and to involve other key union and management leaders in the SWC's learning process.

In summary, the combination of multiple sources of quantitative and qualitative data allowed us to design and implement as well as document the development, successes, and failures of this pilot project intervention over time. Qualitative data from field notes and focus groups provided the foundation from which recommendations for diffusion were developed. Quantitative data from the periodic evaluation surveys validated the qualitative findings, counteracting the danger of overweighing data from focus groups and SWC discussions in which the strongly voiced perspectives of some individuals might have led to unfounded generalizations.

\section{CONCLUSIONS}

As the evidence presented here suggests, an action research process which integrates multiple methods can be an effective way to meet both research and action goals. The SWC's ability to discover and meaningfully address what appear to be key organizational sources of stress was a result of the mutual learning and development process between the research team and committee members. 
This process was guided by the joint effort to collect and interpret multiple types of data, to identify additional information needs on an ongoing basis, and to continuously question our assumptions of what is really happening in the organization. The commitment to "going back to the data" or collecting information where there was none has allowed the group to surmount numerous difficult issues that could easily have turned into ideological, political, or interest group disputes. In the committee at least, the action research process appears to be strongly embedded.

Furthermore, since the interaction between researchers and organizational participants is a key factor in the success or failure of this type of project, a data-based evaluation of project outcomes requires extensive documentation of this interaction. The integration of multiple sources of data collected on an ongoing basis, helps counteract-though not resolve - the difficulty of linking the effects of the interventions to the outcomes studied in the dynamic environment of an organization which is part of an industry in transition.

\section{Limitations}

Though this approach has been extremely useful, rewarding, and stimulating, there have been a number of limitations. Combining qualitative and quantitative data requires a research team with expertise in these methods. We were fortunate to establish a multi-disciplinary team involving persons trained in health education, occupational health, epidemiology, adult education, labor relations, and sociology, in which some team members' strengths were in the use of quantitative methods, and others' expertise was in the collection and analysis of qualitative data. Common to all of us is an appreciation of each other's contribution and an understanding of the advantages of interweaving different approaches. The development of an effective working relationship required mutual training and an emphasis on collaborative team building.

In addition, combining various data sources for problem definition, illumination of meaning, and triangulation, is time consuming, labor intensive, and thus expensive. It can also result in an overabundance of data. The extensive use of qualitative data in the form of interviews, ethnographic field notes, and participant observation on an ongoing basis fosters the proliferation of data. The resulting sense of not really being able to do justice to the reams of data at hand is a frustration well known to many qualitative researchers. Similarly, the accumulation of longitudinal quantitative data also often goes far beyond the key questions and hypotheses of primary interest to the researcher, leaving unexamined numerous relationships between different variables. As we have explored elsewhere, the emphasis on valid research methods can also lead to tension between the research and intervention goals of the project and therefore between researchers and the organization members who invariably value intervention outcomes over research outcomes. The demands created by the use of multiple methods, absent careful attention to balancing research and intervention goals, can exacerbate that tension. ${ }^{32.39}$

Another limitation of the multi-method approach is that it is still not widely recognized and valued as a viable research strategy-at least in mainstream 
social science. We hope that increasing attention in the literature to articles that describe the value and provide examples of research designs using both quantitative and qualitative data will begin to alleviate this skepticism. The issues mentioned do not present insurmountable problems if addressed with careful planning and appropriate resources. They offer great promise for getting inside the "black box" of organizational change efforts.

\section{Implications for Health Education}

Within the field of health education, whether one is involved in addressing basic research questions, or conducting and evaluating interventions, or both as described here, the integration of multiple methods represents a useful strategy. Since evaluation is a critical aspect of all health education endeavors, it is important to keep in mind that comprehensive evaluation, to be meaningful, has to be "process as well as outcome oriented, exploratory as well as confirmatory, and valid as well as reliable", (p. 18). No single method provides the data needed to address these diverse demands.

Needs assessment, intervention design and implementation, evaluation, and diffusion are key program components familiar to all health educators. As presented here, the use of multiple types of data provided a broad-based, crossvalidated identification and in-depth understanding of the problems and needs in the worksite, and guided the development of interventions that were appropriate to the setting. These same methods in turn, were helpful in assessing the process and impact of the interventions. This is particularly important for health education, in which we not only need to be able to describe the results of our interventions, but also to document what worked, what did not work and why. Failure to learn from the process of our interventions tends to result in unsuccessful diffusion efforts. Through the use of multiple methods, we can identify the main requirements for success along with the likely pitfalls-principles of practice that can be diffused to enhance the field. If, as Alderfer ${ }^{41}$ notes, "an essential quality of the scientific method is a process of continuing correction" 41 (p. 66) then the utilization of multiple methods appears to become imperative for the goal of increasing our understanding of complex, continuously changing social realities.

There are obvious implications for health education training. We need to facilitate learning opportunities for qualitative and quantitative methods and their integrative use. Thus, for example, just as statistics and survey methods courses are often required in the curriculum for master's students, so should courses in qualitative methods be provided. In all instances, such courses should be made applicable for practice as well as research purposes. The action research approach is particularly well suited to provide the conceptual framework for teaching and implementing the integration of multi-method research and intervention designs.

\section{References}

1. Trow M: Comment on "participant observation and interviewing: A comparison." Human Organization 16:33-35, 1957. 
2. Schein EH: The Clinical Perspective in Fieldwork. Beverly Hills, CA, Sage Publications, 1987.

3. Reichardt CS, Cook TD: Beyond qualitative versus quantitative methods, in Cook TD, Reichardt CS (eds); Qualitative and Quantitative Methods in Evaluation Research. Beverly Hills, CA, Sage Publications, 1979.

4. Fielding NG, Fielding JL: Linking Data. Beverly Hills, CA, Sage, 1986.

5. Berg DN, Smith KK: Exploring Clinical Methods for Social Research. Beverly Hills, CA, Sage Publications, 1985.

6. Susman GI: An assessment of the scientific merits of action research. Administration Science Quarterly 23:582-603, 1983.

7. Peters M, Robinson V: The origins and status of action research. Journal of Applied Behavioral Science 20:113-124, 1984.

8. Mullen PD, McCuan RA, Iverson DC: Evaluation of health education and promotion programs: A review of qualitative approaches. Advances in Health Education Promotion 1:467-498, 1986.

9. McLeroy KR, Bibeau D, Steckler A, Glanz K: An ecological perspective on health promotion programs. Health Education Quarterly 15:351-378, 1988.

10. Kemmis S: Action research, in Anderson DS, Blakers C (eds): Youth, Transition \& Social Research. Potts Point, NSW, Australian National University Press, 1983.

11. Susman G, Evered R: An assessment of the scientific merits of action research. Administration Science Quarterly 23:582-603, 1978.

12. Katz D, Kahn R: The Social Psychology of Organizations. New York, Wiley, 1978.

13. House JS: Work Stress and Social Support. Reading, MA, Addison-Wesley, 1981.

14. Levi L: Preventing Work Stress. Reading, MA, Addison-Wesley, 1981.

15. Holt RR: Occupational stress, in Goldberger L, Breznitz S (eds); Handbook of Stress: Theoretical and Clinical Aspects. New York, Free Press, 1982.

16. Cottington EM, House JS: Occupational stress and health: A multivariate relationship, in Baum AR, Singer JE (eds); Handbook of Psychology and Health (Vol. 5). Hillsdale, NJ, Erlbaum, 1986.

17. Israel BA, Schurman SJ, House JS: Action research on occupational stress: Involving workers as researchers. International Journal of Health Services 19:135-155, 1989.

18. Dexter L: Elite and Specialized Interviewing. Evanston. IL, Northwestern University Press, 1970.

19. Miles MB, Huberman AM: Qualitative Data Analysis: A Sourcebook of New Methods. Beverly Hills, CA, Sage, 1984.

20. Basch CE: Focus group interview: An underutilized research technique for improving theory and practice in health education. Health Education Quarterly 14:411-448, 1987.

21. Krueger RA: A Practical Guide for Applied Research. Beverly Hills, Sage, 1988.

22. Elden $\mathbf{M}$, Levin $\mathbf{M}$ : Cogenerative learning: Bringing participation into action research, in Whyte WF (ed): Participatory Action Research. Newbury Park, CA, Sage, 1991.

23. Whyte WF: Interviewing in field research, in Adams RN, Preiss SS (eds); Human Organization Research: Field Relations and Techniques. Homewood, IL, Dorsey, 1960.

24. Chesler M: Professionals' views of the dangers of self-help groups. Working Paper \#345, Center for Research on Social Organization, University of Michigan, Ann Arbor, MI, 1987.

25. Israel BA, House JS, Schurman SJ, Heaney CA, Mero RP: The relation to personal resources, participation, influence, interpersonal relationships and coping strategies to occupational stress, job strains and health: A multivariate analysis. Work and Stress 3:163-194, 1989. 
26. Klitzman S, House JS, Israel BA, Mero RP: Work stress, nonwork stress, and health. Journal of Behavioral Medicine 13:221-243, 1990.

27. Hammersley M, Atkinson P: Ethnography: Principles in Practice. London, Tavistock, 1983.

28. Campbell DT. Fiske DW: Convergent and discriminant validity by the multi-trait, multi-method matrix. Psychology Bulletin 56:81-105, 1959.

29. Denzin NK: The Research Act in Sociology. London. Butterworth, 1970.

30. Yin RK: Case Study Research: Design and Methods. Beverly Hills, CA, Sage, 1984.

31. Ingersoll-Dayton B: Combining methodological approaches in social support research. Paper presented at the Annual Meeting of the American Psychological Association, Washington, DC, August 1982.

32. Cummings T, Mohrman S: Self-designing organizations: Towards implementing quality-of-work-life innovations, in Woodman RW, Pasmore WA (eds); Research in Organizational Change and Development (Vol. 1). Greenwich, CT, Jai Press Inc., 1987.

33. Jick TD: Mixing qualitative and quantitative methods: Triangulation in action, in Van Maanen J (ed); Qualitative Methodology. Beverly Hills, CA, Sage, 1975.

34. Sieber SD: The integration of fieldwork and survey methods. American Journal of Sociology 78:1335-1359, 1973.

35. Schein EH: Process Consultation (Vol. 2). Reading, MA, Addison-Wesley, 1987.

36. Camman C, Lawler EE, Ledford GE, Seashore SE: Management-Labor Cooperation and Quality of Worklife Experiments: Comparative Analysis of 8 Cases. U.S. Department of Labor, 1984.

37. Cooke WN: Labor-Management Partnerships: New Directions or Going in Circles? Kalamazoo, MI, Upjohn Institute, 1990.

38. Goodman PS: Realities of improving the quality of worklife: Quality of worklife projects in the 1980s. Proceedings of the 1980 Spring Meeting, Industrial Relations Research Association, Madison, WI, 1980.

39. Israel BA, Schurman SJ, Hugentobler MK: The relationship between organization members and researchers in conducting action research: Values, skills, control, politics, and rewards. Submitted for review.

40. Hackman RJ: On seeking one's own clinical voice: A personal account, in Berg DN, Smith KK (eds); Exploring Clinical Methods for Social Research. Beverly Hills, CA, Sage, 1986.

41. Alderfer CHJ: Freud, a potential family theorist. Network 2:9-10, 1985. 